\title{
On the Organic Relation Between Carrying Out Student Health Education and University Physical Education Reform in Colleges and Universities
}

\author{
$\mathrm{Xu}$ Zaifei
}

\author{
Shandong Vocational College of Economics (Department of Science and Humanities) \\ Weifang City, Shandong Province
}

\begin{abstract}
with the continuous development and improvement of the field of education in our country, the requirements for physical education teaching in colleges and universities have gradually changed. Nowadays, the teaching of physical education in colleges and universities pays more attention to students'physical health and physical accomplishment, and pays more attention to students'concept of physical education and health, rather than blindly improving students'sports skills and entertaining students'amateur life. Health education is an important educational content in colleges and universities at present, and it is closely related to the reform of physical education. How to grasp the method of health education and promote the reform of physical education teaching is a key problem to be considered in colleges and universities at present. This paper briefly introduces the present situation of physical education in colleges and universities and the significance of implementing students'health education The relationship between health education and college physical education reform is to explore the concrete methods of implementing students'health education and its effective strategies to promote physical education reform.
\end{abstract}

Keywords: universities, students, health education, physical education reform, organic relations

\section{浅谈高校实施学生健康教育与大学体育教学改革的有机 联系 \\ 徐再飞 \\ 山东经贸职业学院 (科学与人文系) 山东省潍坊市 261011}

\begin{abstract}
摘要
随着我国教育领域的不断发展与完善, 对高校体育教学的要求也逐渐转变, 现如今高校体育教学的更 加关注学生的身体健康与体能素养, 关注学生的体育与健康观念, 而非一味的提高学生的体育技能水 平，娱乐学生的业余生活。健康教育是现阶段高校中的重要教育内容，其与体育教学改革之间具有密 切联系, 如何把握健康教育方法, 推动体育教学改革是当下各高校需要重点思考的问题。本文简要高 校体育教学现状及实施学生健康教育的意义与健康教育与大学体育教学改革之间的有机联系, 对高校 实施学生健康教育的具体方法及其推动体育教学改革的有效策略进行深入探究。

关键词：高校；学生；健康教育；体育教学改革；有机联系

\section{1. 前言}

健康教育与高校体育教学改革之间具有密切联系, 又有一定的区别, 健康教育是一门研究保健知识的课程, 是影响学生去群体行为, 消除体育危险因素, 提高学生

身体素质, 预防疾病, 促进学生身心健康发展的学科。 现如今, 高校体育教学存在较多的问题, 影响了体育教 学效果, 比如: 教学方法落后、教学内容单一等。基于 此, 教师可以将健康教育与体育教学改革相融合, 将健 康教育融入体育教学全过程, 把握健康教育方法, 丰富 体育教学内容与教学形式, 将促进学生身心健康发展、
\end{abstract}


培养学生体育与健康观念为教育核心, 引导学生的行为, 强化学生的健康意识, 为学生今后的发展奠定基础。

\section{2. 高校体育教学现状及实施学生健康教育的 意义}

(一) 高校体育教学现状

在现阶段的高校体育教学中, 一些教师过分关注学 生的基础训练及体育技能的掌握, 忽略了对学生身体素 质的锻炼与培养, 采用的教学方法也较为老套, 一直是 通过教师演示, 学生模仿的形式展开教学, 不仅无法激 发学生对于体育运动的热情, 更不能够平衡学生的体能 与健康发展需求, 不能够实现自主发展。落后的教学手 段导致学生的身体素质无法得到提升, 从根本上忽略了 学生全面发展的重要价值, 促使体育课程逐渐沦落为 “体能课程”, 丧失了体育课程对于培养学生健康意识, 强化学生体育精神, 提高学生身体机能的目的, 阻碍学 生的身心健康发展 ${ }^{[1]}$ 。

在现阶段的高校体育教学中, 体育教师在课堂教学 中开展教学活动的方式较为单一, 体育教学内容同样单 一, 比如: 田径训练、篮球训练、足球训练等。体育教 师将教学精力投注于竞技体育运动教学中, 甚至会让学 生反复练习同一个动作, 占用了大部分的体育课堂教学 时间; 教学内容单一、教学方法单调, 导致课堂氛围枯 燥乏味, 无法激发学生的体育教学活动参与兴趣, 不能 够调动学生参与体育运动的积极性, 同样也不能够让学 生认识到体育与身体健康之间的关系, 无法培养学生形 成良好的体育健康观念, 违背了高校体育开设初衷。

（二）高校实施学生健康教育的意义

健康的身体是大学生进入社会参与工作, 为社会发 展做出贡献的基础与前提, 是我国蓬勃发展的重要元素, 是中华民族旺盛生命力的主要体现形式。在大学生学习 与成长的过程中, 如何提高大学生的身体素质, 促进大 学生身心健康发展是社会各界重点关注的问题, 是高校 开展体育教育工作的重要任务。开展健康教育, 能够增 强大学生的身体素质, 提高大学生的健康水平, 促使学 生德、智、体、美、劳全面发展, 能够培养学生形成健 康体育观念, 强化学生对于体育运动的积极性, 更能够 增进大学生的体质健康水平 ${ }^{[2]}$ 。

\section{3. 健康教育与大学体育教学改革之间的有机 联系}

健康教育能够为大学体育教学改革提供具体的健 康标准。高校是为社会输送高素质人才的储备库, 但是 现阶段很多大学生缺乏基本的保健意识与自主保健知 识, 其身心健康情况不太乐观, 在体检中经常会被检查 出一些常见的疾病, 呈现出亚健康发展趋势, 比如: 肥 胖症、少年高血糖、近视眼、远视眼等, 且呈现出逐渐 上升趋势; 这种情况主要是由于学生缺乏健康认知导致 的。在高校健康教育中, 教师可以明确提出“十条标准”,
比如: 第一, 具有充沛精力, 能够轻松应对日常生活与 学习任务; 第二, 心态乐观, 态度积极, 能够主动承担 责任; 第三, 善于休息, 具有良好的睡眠; 第四, 应变 能力较强, 能够很好的适应外界环境的变化; 第五, 能 够抵抗传染病与一般感冒; 第六, 体重得当, 身材匀称; 第七, 眼睛明亮, 眼䀦不发言; 第八, 牙齿清洁、牙龈 颜色正常; 第九, 头发有光泽, 无头皮屑; 第十, 肌肉 皮肤有弹力、走路轻松。结合上述十条标准, 教师能够 将其作为开展体育健康教育, 推动体育教学改革的主要 参考, 培养学生形成良好的健康观念, 并且能够通过体 育运动保持身体的健康状态 ${ }^{[3]}$ 。

健康教育在体育教学改革中占有重要地位。随着教 育改革的深入发展, 我国的体育教学逐渐由原本的 “体 操科” 发展为 “体育课”, 为我国培养高素质人才做出 了巨大的贡献, 充分发挥了体育教学的功能。随着现代 社会的快速发展, 人们越来越关注 “健康” , 原有的体 育教学课程已经无法满足现代社会大学生的全面发展 需求。因此, 健康教育的融入能够满足素质教育改革需 求, 改变了以往的 “三基” 模式, 将体育教学仅仅围绕 “健康教育”, 培养学生健康观念, 教授给学生健康知 识与保健防范, 促使学生形成终身体育、终身健康的思 想观念, 促进学生全面发展。

高校体育教学改革推动了体育与健康一体化发展 进程, 现代社会经济环境的变化影响了人们的日常生活 方式、思维方式与情感思想价值, 因此, 健康观念需要 建立在现代社会思想体系的基础上, 要将体育教学与健 康教育相融合, 将大学生的身体健康推向一个新的阶梯, 培养出既具有良好素养, 又具有健康观念的复合型人才 [4]。

\section{4. 高校实施学生健康教育的具体方法}

（一）帮助学生改变不良生活习惯

在体育课堂教学中, 学生的不良生活习惯主要体现 在睡眠不足、饮食不规律、缺乏运动等方面, 导致学生 在体育课堂上的表现不佳, 不能够积极主动的参与体育 运动, 无法通过体育课程锻炼学生的身体素质, 掌握健 康保健知识。教师要想在体育课堂中开展健康教育, 就 要认真分析学生产生不良生活习惯的云原因, 一席观察 学生的精神面貌, 若发现学生的精神较差, 不能够主动 参与教师提出的体育活动, 就要主动关心学生的日常生 活, 从学生的角度出发考虑学生的问题; 教师要在体育 课堂中安排见习环节, 让不能够参与体育运动的学生进 行 “见习”, 禁止这些学生参与剧烈运动, 要适当开展 批评教育, 避免学生过度沉溺网络, 引导学生合理饮食, 正常休息, 促使学生形成健康生活习惯意识 ${ }^{[5]}$ 。

(二) 关注学生的心理健康

要想在体育教学中开展健康教育, 就不仅仅要关 注学生的身体健康, 更要关注学生的心理健康, 要根据 《全国普通高等学校体育课程教学指导纲要》内容, 结 合心理健康教育要求, 重点关注学生的身心变化, 引导 学生形成良好的价值观念与心理思想模式, 为学生的身 
培养学生的身体素质, 提高学生心理健康水平作为课程

心健康发展奠定基础。在体育课堂教学中, 教师要考虑 到本院校学生的实际情况, 尤其是女生较多的情况。本 院校为财经类院校, 院校中存在 “女多男少” 的情况, 因此教师要重点关注班级女生的情绪状态, 若发现有个 别女生情绪低落, 不服从教师安排, 则不要轻易训斥和 责备, 而是要轻声询问其身体状态, 合理安排其进行休 息, 若还是反应较弱, 则可以先上课, 在课下时间与学 生进行沟通与交流; 若发现学生是由于家庭问题、情感 问题、健康问题、学习压力等导致的情绪低落, 则要适 当引导, 并且将其与导员及心理辅导教师取得联系; 若 发现是身体原因, 则可以为其提供合理的健康建议, 让 学生感受到自己是被关心的, 促使学生心理健康发 展。

\section{（三）选择合适的运动环境}

要想在体育教学中开展健康教育, 就要选择合适的 体育运动环境, 让学生在良好的环境中开展体育活动。 一般情况下, 高校体育课程都是在室外开展的, 或者是 在室内体育馆开展教学活动, 主要是为了让学生通过体 育运动锻炼, 形成吃苦耐劳的精神与良好的生活习惯与 体育运动习惯。但是, 从身体健康的角度出发, 在一些 特殊的环境中开展体育运动并不利于学生的身体健康, 甚至会损坏学生的身体健康。比如: 在冬季雾䨪天气, 教师在室外开展足球教学, 就会让学生的肢体长时间暴 露在寒冷的空气中, 差生冻伤; 还会促使学生吸入雾䨪, 影响学生的呼吸系统健康; 更会降低学生的体育积极性。 基于此, 教师要结合外界天气环境, 调整教学场所, 比 如: 在夏季高温、冬季严寒、雾䨪、暴雨天气等, 将室 外教学调整至室内体育馆教学, 或者在普通教室开展健 康保健知识教育, 实现健康教育目标。

（四）培养学生形成良好的运动习惯

要想在体育教学中开展健康教育, 就要培养学生形 成良好的体育运动习惯。在体育教学中培养学生形成健 康的体育运动观念是一项较为艰巨的任务。现阶段大学 生个性愈发鲜明, 每名学生都有自己的喜好与体育学习 倾向, 就会出现 “有的学生特别热爱体育运动, 专注于 运动”、“有的学生不喜欢体育运动, 甚至厌恶运动” 两极化的情况, 基于此, 教师要引导学生调整观念, 要 认识到 “过度运动” 与 “运动不足” 的危害, 重点讲解 每项运动能够起到的效果, 通过丰富多样的教学活动, 吸引学生的关注, 促使学生都能够找到适合自己的运动, 从而形成健康、正确的体育运动与健康观念, 合理开展 体育锻炼。

\section{5. 高校实施学生健康教育推动体育教学改革 的有效策略}

(一) 转变体育教学观念, 创新体育教学活动形式 要想通过健康教育推动体育教学改革, 教师就要积 极转变课堂体育教学观念, 创新体育课堂教学形式与教 学活动, 激发学生的体育运动兴趣。高校体育教师在开 展体育教学改革的同时, 要明确提出体育课程改革目标, 从根本上践行 “以人为本, 健康第一” 的理论思想, 将
改革的出发点, 在课堂教学的过程中融入一些能够激发 大学生兴趣的项目，具体可以参考 “极限挑战” 等综艺 活动, 引起学生的思想共鸣, 促使学生积极主动参与体 育课堂教学活动, 培养学生自主运动观念, 强化学生的 运动能力, 帮助学生提高免疫力, 促进学生身心健康发 展。 教育效用

（二）整合体育与健康观念, 强化体育教学的健康

要想通过健康教育推动体育教学改革, 就要优化整 合体育与健康教育观念, 调整体育课程结构, 完善传统 体育课程教学结构, 关注学生的体制健康, 发挥各方面 的教学作用。在大一两个学期的体育课程教学中, 教师 可以结合基础类体育教学内容, 将其作为培养学生体育 锻炼习惯的主要内容, 培养学生形成 “衬砌跑步”、“定 期打排球” 等良好的体育运动习惯; 在大二两个学期的 体育课程教学中, 教师可以适当引进体育通识方面的内 容, 引导学生参加体育俱乐部, 或者参与体育学生会社, 强化体育与健康教育目标。

(三) 整合课内外体育教学, 提高学生的身体健康 水平

要想通过健康教育推动体育教学改革, 就要优化整 合校内教学资源与校外教学资源, 拓展学生的体育运动 与学习场域, 提高学生的身体健康水平。教师可以在原 有晨起跑步的基础上, 结合课外体育活动, 设置特定的 课外体育运动时间, 与课堂教学形成内在联系; 教师可 以调整晨跑的时间与内容, 将其作为体育课堂教学部分, 从而激发学生的学习新区, 还要将 “跑步” 作为体育课 程学习评价的重要标准, 让学生认识到课外体育活动的 重要性, 主动参与活动, 锻炼学生身体健康。

(四) 从学生健康角度出发, 制定健全体育教学计 划

要想通过健康教育推动体育教学改革, 教师就要重 点关注学生的身体健康, 结合大学生的实际身体素质情 况, 科学合理编制体育与健康教育方案, 提高高校体育 教学的有效性与可靠性, 形成具有现代高校健康教育特 色的体育教学体系, 教师可以将原有的体育基础课程作 为依托, 设置适当的探索活动与任务挑战活动, 比如: “1/4 马拉松挑战任务”、“体育健康知识问答赛任务” 等, 不强制学生参与, 但是鼓励学生参与, 参与的学生 能够获取优秀记录, 参与挑战成功的学生则能够增加 1-2 分的学分, 从而强化高校体育健康教育效用, 推动 体育教学改革。

\section{6. 结语:}

总而言之, 健康教育能够为高校体育教学改革提供 具体的健康标准, 能够强化体育教学的效用, 在体育教 学改革中占有重要地位; 体育教学改革能够推动高校体 育教学与健康教育一体化发展, 深化 “健康与体育” 教 育。高校体育教师在教学改革过程中要关注学生的身体 健康, 将学生的身体发展作为教学目标; 在实际教学过 
程中, 要积极调整体育教学观念, 整合校内外体育教学, 制定健全体育教学计划, 从而强化体育教学的健康教育 效用, 提高学生的身体健康水平。

\section{REFERENCES}

[1] Pan Shaowei. China's basic education physical education (and health) curriculum reform and development of 70 years review and prospects [J]. Chinese School Physical Education,2019(10):10-13.

[2] Qiu Liqiang, Liao Shanggui. Reform of physical education in colleges and universities under the thought of lifelong physical education [J]. Journal of Nanchang Institute of Education,2019,34(04):92-95.

[3] Guo Yu. Analysis and Countermeasures of the Role of Physical Education in College Students'Quality Education [J]. New West,2019(02):145156.

[4] Guan Lu. A Preliminary Study on the Reform of Physical Education Teaching in Colleges and Universities [J]. Journal of Hubei correspondence University,2016,29(17):160-161.

[5] Sheng Jianying, Zheng Zhongbo. On the innovation of physical education teaching mode in colleges and universities must conform to the renewal of health concept [J]. Rule of law and economy (early days),2012(10):79-80. 